\title{
Influence of climatic conditions of the introduction period and varietal characteristics of black currant (Ribes nigrum L.) on the effectiveness of culture initiation in vitro
}

\author{
T.M. Khromova*, L.V. Tashmatova, O.V. Matsneva, and V.V. Shakhov \\ Russian Research Institute of Fruit Crop Breeding (VNIISPK), Zhilina, Orel district, Orel region, \\ Russian Federation
}

\begin{abstract}
The article presents data from the effectiveness studies of the initial introduction stage of black currant (Ribes nigrum L.) into in vitro culture depending on the introduction period and the corresponding climatic conditions. The research objects were varieties of black currants selected by the Russian Research Institute of Fruit Crop Breeding: Azhurnaya, Orlovskaya serenada, Ocharovanie, Chudnoye mgnovenye. The introduction into in vitro culture was carried out in several periods characterized by different physiological states of the explants: the period of dormancy release (mid-March), the period of active growth (June), and the period of growth decay (mid-September). The source material in the spring and autumn periods were the buds of one-year stiffened shoots, in the summer introduction period - the buds of growing green shoots. The cultivation was carried out on Murashige-Skoog medium supplemented with 6 -BAP $(0.5 \mathrm{mg} / \mathrm{l})$. It was noted that the survival rate of explants is determined by the physiological state of the source material due to the corresponding agro-climatic conditions during the introduction period, as well as the genotypic characteristics of the varieties. Thus, explants isolated during the active growing season are characterized by a higher and more stable survival rate. When explants were cultivated in spring and autumn, the physiological state of the explants and their survival rate were influenced by the genotypic response of varieties to the corresponding agroclimatic conditions.
\end{abstract}

\section{Introduction}

The implementation of the regenerative potential of plant organisms, which underlies clonal micropropagation, depends on the influence of a combination of genetic, physiological, chemical and physical factors at all stages of cultivation: genotype, age of the initial plant, seasonality of isolation, size of the initial explant, cultivation conditions [1-16].

\footnotetext{
*Corresponding author: hromova@vniispk.ru
} 
One of the most important physiological factors is the isolation time of the explant (season of the year). Tissues and organs isolated at the moment of plant vegetation have a higher morphogenetic potential compared to tissues taken as an explant during deep and forced dormancy $[7,8]$.

The purpose of these studies was to study the effectiveness of the initial introduction stage of black currant into in vitro culture depending on the introduction period and the corresponding climatic conditions, as well as on the genotypic characteristics of varieties using the example of promising varieties selected by the Russian Research Institute of Fruit Crop Breeding.

\section{Materials and methods}

The studies were carried out in 2018-2021 according to generally accepted methods [7, 15, $17,18]$.

The objects of research were black currant varieties of medium ripening: Azhurnaya, Orlovskaya serenada, Ocharovanie, Chudnoye mgnovenye.

The introduction into in vitro culture was carried out in three periods characterized by different physiological states of the explants: the period of the dormancy release (midMarch), the period of active growth (June), and the period of growth decay (mid-September). In the spring, buds from annual stiffened shoots were used as the source material. To stimulate the process of exiting dormancy, the shoots were placed in a vessel with water and kept at a temperature of $22-24{ }^{\circ} \mathrm{C}$ until a green cone appeared. In the summer period of introduction, the sources of explants were the buds of growing green shoots. In the autumn period, the source material was the closed buds of annual stiffened shoots.

Meteorological observation data for the period from January 2018 to April 2021 were used to characterize climatic conditions, which were obtained at a meteorological station located on the territory of the Russian Research Institute of Fruit Crop Breeding. It is noted that the years of research were characterized by contrasting weather conditions (Figure 1).

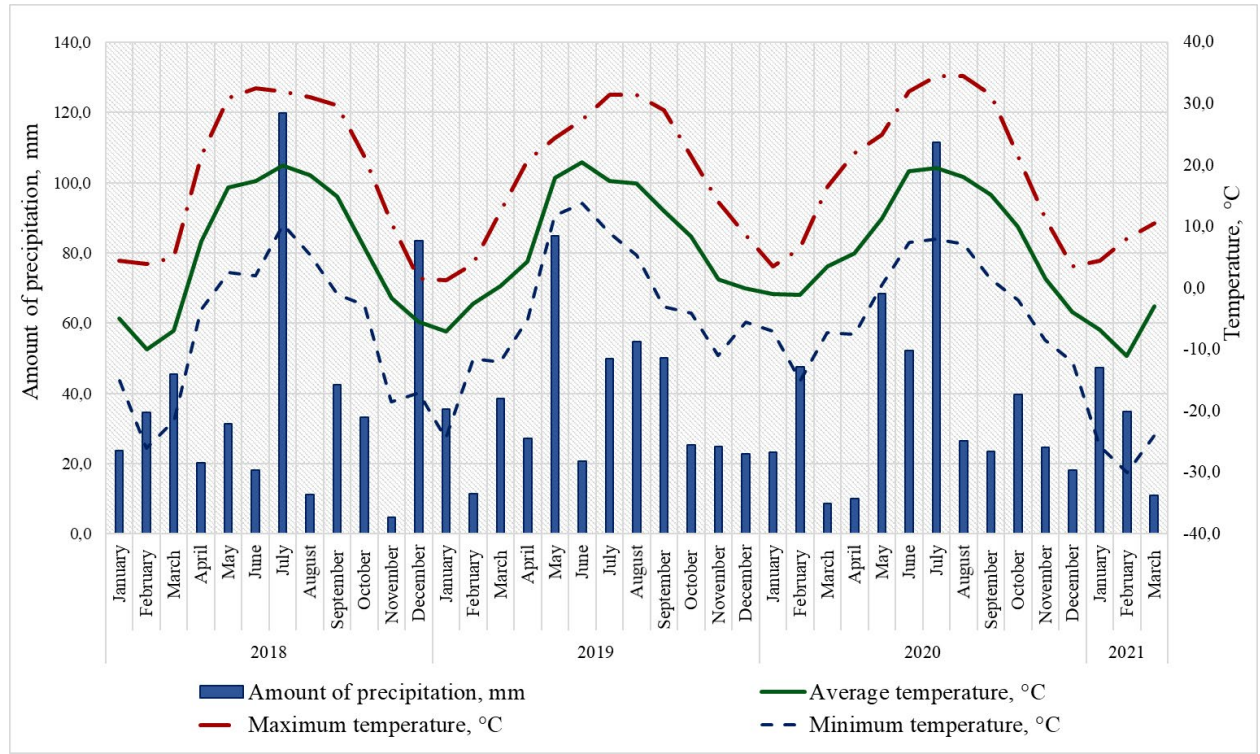

Fig. 1. Climatic conditions during the years of research. 
The plant material was sterilized using mercury dichloride $\left(\mathrm{HgCl}_{2}\right)$ at a concentration of $0.1 \%$ with an exposure time of $10 \mathrm{~min}$.

For the cultivation of bud-derived meristematic apexes (actual meristems with primordium and an underlying tissue layer of the origin cone measuring 1-2 mm), a modified Murashige-Skoog medium was used with the addition of cytokinin 6 -BAP $(0.5 \mathrm{mg} / \mathrm{L})$, an antioxidant component of ascorbic acid $(10 \mathrm{mg} / \mathrm{l})$ and a triple amount of iron chelate (Figure 2).

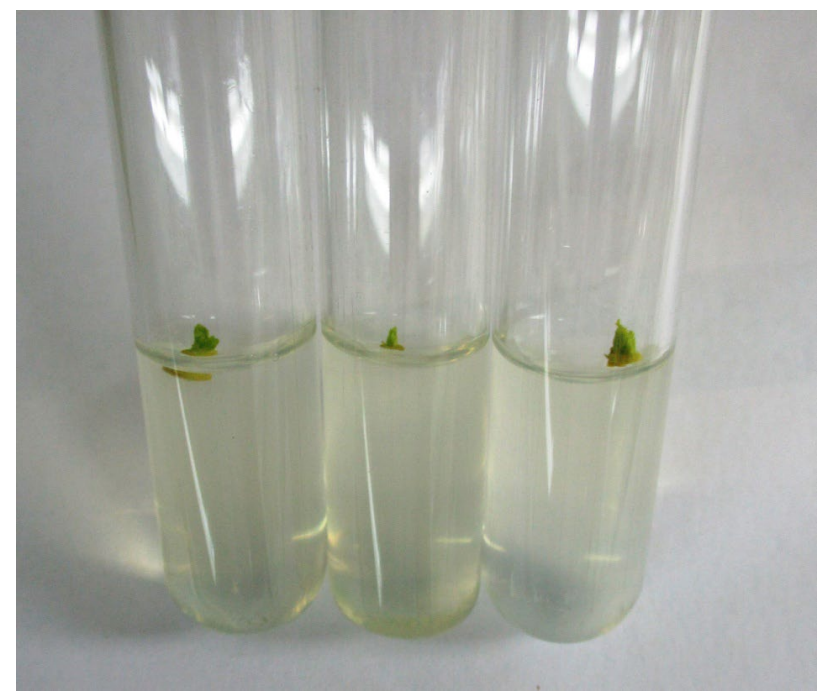

Fig. 2. Meristematic apexes of black currant (Chudnoye mgnovenye variety) at the time of introduction into culture.

Statistical processing was carried out using the Microsoft Excel 2016 computer program.

The degree of influence of the variety and climatic conditions of the introduction period on the physiological state of the source material and the effectiveness of in vitro culture initiation were assessed using the variation coefficient of the indicator $(\mathrm{CV})$. The value of $\mathrm{CV} \leq 10 \%$ is a weak variability of the indicator, at $10 \% \leq \mathrm{CV} \leq 20 \%$ - medium and CV more than $20 \%$ - high.

To assess the indicator's significance level, the Student's test (T) was used with the significance of the indicator $\mathrm{P} \leq 0.05$.

\section{Results and discussion}

The success of the introduction into in vitro culture is largely determined by the timing of obtaining explants. A number of researchers have found that it is advisable to use large, formed axillary buds without covering lamellas isolated in mid-summer or early autumn. The survival rate of explants taken in the spring and later autumn periods is significantly lower due to the large proportion of dead and infected shoots $[14,16]$. However, N.V. Kuharchik et al. considers the best time for introduction into in vitro culture to be February - early April - the phase of vegetative buds' dormancy release [15].

As a source of meristems in this study, the buds of annual shoots obtained during the period of dormancy release (mid-March), active growth (mid-June), and growth decay (midSeptember) were used.

The research results are presented in table 1. 
Table 1. Viability of explants depending on the period of introduction and varietal characteristics, 2018-2021.

\begin{tabular}{|c|c|c|c|c|c|}
\hline \multirow{2}{*}{ Varieties } & \multirow{2}{*}{ Vitality indicators (in \%) } & \multicolumn{4}{|c|}{ Spring period of introduction into in vitro culture } \\
\hline & & 2019 & 2020 & 2021 & CV \\
\hline \multirow[t]{2}{*}{ Azhurnaya } & Proportion of viable explants* & 79 & 54 & 86 & 18.76 \\
\hline & Necrosis** & 18 & 42 & 12 & 54.01 \\
\hline \multirow{2}{*}{$\begin{array}{l}\text { Orlovskaya } \\
\text { Serenada }\end{array}$} & Proportion of viable explants & 77 & 50 & 94 & 24.60 \\
\hline & Necrosis & 21 & 48 & 6 & 69.51 \\
\hline \multirow[t]{2}{*}{ Ocharovaniye } & Proportion of viable explants & 71 & 64 & 62 & 5.54 \\
\hline & Necrosis & 28 & 36 & 38 & 12.71 \\
\hline \multirow{2}{*}{$\begin{array}{l}\text { Chudnoye } \\
\text { mgnoveniye }\end{array}$} & Proportion of viable explants & 44 & 18 & 82 & 54.61 \\
\hline & Necrosis & 53 & 78 & 16 & 51.98 \\
\hline \multicolumn{2}{|c|}{ Student's criterion, $\mathbf{T}$ (for indicator 1 ) } & \multicolumn{2}{|c|}{$\mathrm{T}_{2019-2020}=1.7$} & \multicolumn{2}{|c|}{$\mathrm{T}_{2020-2021}=2.9$} \\
\hline \multirow{3}{*}{\multicolumn{2}{|c|}{ Student's criterion, $\mathbf{T}$ (for indicator 2 ) }} & \multicolumn{2}{|c|}{$\mathrm{T}_{2019-2020}=1.7$} & \multicolumn{2}{|c|}{$\mathrm{T}_{2020-2021}=2.8$} \\
\hline & & \multicolumn{4}{|c|}{$\begin{array}{c}\text { Summer period of introduction into in vitro } \\
\text { culture }\end{array}$} \\
\hline & & 2018 & 2019 & 2020 & $\mathrm{CV}$ \\
\hline \multirow[t]{2}{*}{ Azhurnaya } & Proportion of viable explants & 96 & 71 & 95 & 13.28 \\
\hline & Necrosis & 4 & 21 & 5 & 77.89 \\
\hline \multirow{2}{*}{$\begin{array}{l}\text { Orlovskaya } \\
\text { Serenada }\end{array}$} & Proportion of viable explants & 88 & 70 & 95 & 12.49 \\
\hline & Necrosis & 6 & 26 & 5 & 78.42 \\
\hline \multirow[t]{2}{*}{ Ocharovaniye } & Proportion of viable explants & 96 & 67 & 72 & 16.26 \\
\hline & Necrosis & 4 & 29 & 28 & 56.84 \\
\hline \multirow{2}{*}{$\begin{array}{l}\text { Chudnoye } \\
\text { mgnoveniye }\end{array}$} & Proportion of viable explants & 59 & 73 & 95 & 19.87 \\
\hline & Necrosis & 40 & 18 & 5 & 68.79 \\
\hline \multicolumn{2}{|c|}{ Student's criterion, $\mathbf{T}$ (for indicator 1 ) } & \multicolumn{2}{|c|}{$\mathrm{T}_{2018-2019}=1.6$} & \multicolumn{2}{|c|}{$\mathrm{T}_{2019-2020}=3.4$} \\
\hline \multicolumn{2}{|c|}{ Student's criterion, $\mathbf{T}$ (for indicator 2) } & \multicolumn{2}{|c|}{$\mathrm{T}_{2018-2019}=1.1$} & \multicolumn{2}{|c|}{$\mathrm{T}_{2019-2020}=2.1$} \\
\hline & & \multicolumn{4}{|c|}{$\begin{array}{l}\text { Autumn period of introduction into in vitro } \\
\text { culture }\end{array}$} \\
\hline & & 2018 & 2019 & 2020 & $\mathbf{C V}$ \\
\hline \multirow[t]{2}{*}{ Azhurnaya } & Proportion of viable explants & 86 & 67 & 91 & 12.62 \\
\hline & Necrosis & 12 & 29 & 9 & 52.84 \\
\hline \multirow{2}{*}{$\begin{array}{l}\text { Orlovskaya } \\
\text { Serenada }\end{array}$} & Proportion of viable explants & 84 & 90 & 95 & 4.85 \\
\hline & Necrosis & 6 & 9 & 5 & 25.50 \\
\hline \multirow[t]{2}{*}{ Ocharovaniye } & Proportion of viable explants & 82 & 50 & 85 & 21.90 \\
\hline & Necrosis & 12 & 46 & 0 & 100.77 \\
\hline \multirow[t]{2}{*}{$\begin{array}{l}\text { Chudnoye } \\
\text { mgnoveniye }\end{array}$} & Proportion of viable explants & 98 & 11 & 80 & 59.10 \\
\hline & Necrosis & 2 & 77 & 5 & 123.82 \\
\hline
\end{tabular}




\begin{tabular}{|l|l|l|}
\hline Student's criterion, T (for indicator 1) & $\mathrm{T}_{2018-2019}=1.9$ & $\mathrm{~T}_{2019-2020}=2.0$ \\
\hline Student's criterion, T (for indicator 2) & $\mathrm{T}_{2018-2019}=2.2$ & $\mathrm{~T}_{2019-2020}=2.4$ \\
\hline $\begin{array}{l}* \text { Indicator 1 } \\
\text { ** Indicator 2 }\end{array}$ & \\
\hline
\end{tabular}

When introduced into in vitro culture in the spring, it was noted that the buds were differentiated according to the flower type. The isolation of the meristematic apexes was hampered by the presence of large germinal flowers, the small size of the meristems and their location along the periphery. However, the presence of more than one meristem in the buds caused the formation of several regenerants in explants simultaneously (Figure 3).

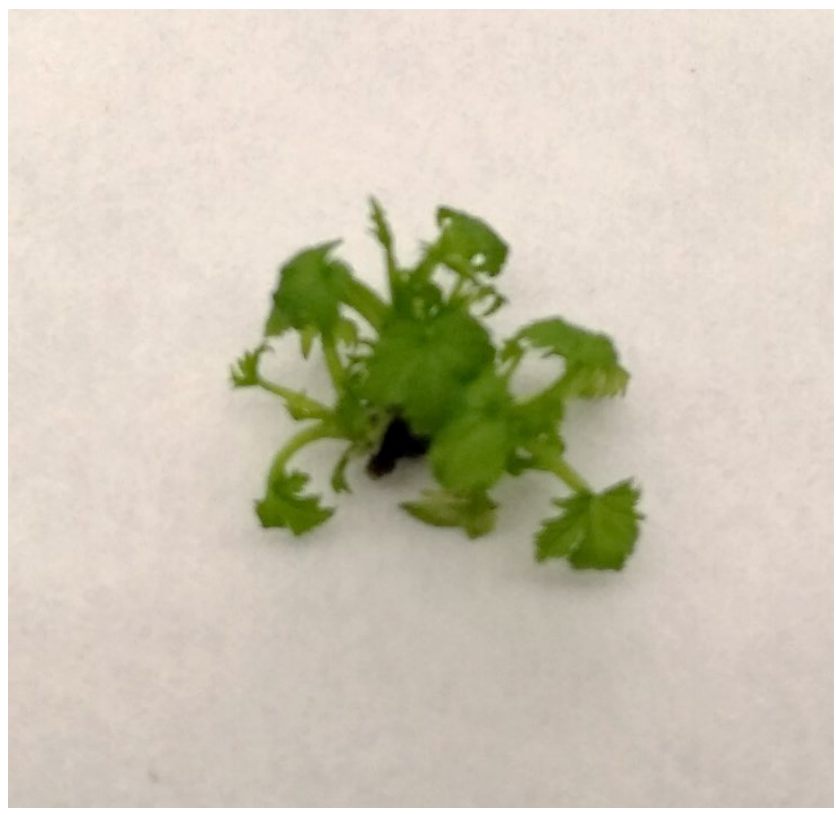

Fig. 3. Formation of several regenerants on one explant in the spring introduction period (Chudnoye mgnovenye variety).

The viability indicators of explants in the spring introduction period in 2019 and 2020 differed insignificantly, while in 2020 and 2021 there were significant differences. The values of the Student's criterion $(T)$ were reliable with the indicator's significance $P \leq 0.05$. The climatic conditions of 2019 and 2020 (warm winters with sharp temperature fluctuations, as well as high positive temperatures in March) contributed to an earlier release of the buds from dormancy. In 2019 and 2020, the development of explants was uneven. The early onset of dormancy release caused a greater openness of the meristems and an increase in the proportion of dead explants, in particular, under the action of a sterilizing agent and due to the growth and necrosis of preserved fragments of germinal inflorescences. In 2019, the proportion of dead explants was $18 \ldots 53 \%$. In 2020 - $36 \ldots 78 \%$, which was due to the initial state of the buds: high positive temperatures in late winter and early March contributed to buds' gemmation, however, a sharp drop to negative temperatures had a traumatic effect on them.

In 2021, due to low temperatures and stable snow cover, the buds were in a state of deep dormancy at the time of obtaining the source material. The buds were characterized by the presence of small germinal buds, and therefore their preservation in the explant did not affect 
the development of meristems, the proportion of dead explants was significantly lower $(6 \ldots$ $38 \%$ ).

Studies have also shown that in the spring, varietal characteristics have a significant impact on vitality indicators. Varieties Azhurnaya, Orlovskaya serenada and Chudnoye mgnovenye reacted to agroclimatic conditions most sharply. The earlier buds' dormancy release in these varieties can reduce the efficiency of in vitro culture initiation by more than $20 \%$.

In the summer introduction period, the apical buds of growing green shoots were growing and had formed meristems. Significant differences between the survival rates in 2019 and 2020 were due to sharper temperature fluctuations in 2019 (about $20^{\circ} \mathrm{C}$ ) during the start of the active growing season. The share of dead explants in 2019 was $18 \ldots 29 \%$.

In the autumn of 2018 and 2020, closed buds differentiated by the flower type served as the sources of explants. The survival rate of the obtained meristems was $82 \ldots 98 \%$ in 2018 , $80 \ldots 95 \%$ in 2020. The weather conditions of 2019 (high temperatures and sufficient humidity) led to the presence of a new growth in early September; the green apexes of the shoots served as the source material during this period. The survival rate of explants was significantly lower and varied significantly by varieties, which was due to the morphological features of the buds. In the plants' shoots of Azhurnaya variety, both the lateral and apical buds had tightly closed covering lamellas. The rudimentary leaves were loosely arranged; formed germinal buds were present. Meristems were small, located along the edges of the origin cone, between leaves, several pieces each. At the same time, no significant differences were found between the apical and lateral buds. The survival rate of this variety's meristems was $67 \%$. In the plants' shoots of Orlovskaya serenada variety, the buds were surrounded by dense covering lamellas. The rudimentary leaves were soft, loosely located, the meristems were large, mostly located in the center of the origin cone, less often on the side. Germinal flowers were found mainly in lateral buds; in apical buds, the number of buds was small. The survival rate of meristems of this variety was $90 \%$. In the plants' shoots of varieties Ocharovanie and Chudnoe mgnovenye, the buds also had dense covering lamellas. The meristems were small, located along the edge of the origin cone between loosely arranged leaves. The central part of the buds was occupied by germinal buds. The survival rate of the meristems of these varieties was $67 \%$; it amounted to $50 \%$ and $11 \%$, respectively.

\section{Conclusions}

Out of the studied cultivation factors when introducing black currant into in vitro culture, the most significant effect is exerted by the isolation time of explants and the corresponding agroclimatic conditions, as well as the genotypic characteristics of varieties. Explants isolated during the active growing season (summer period) are characterized by a higher and more stable survival rate. When explants are cultivated in spring and autumn, the physiological state of the explants and their survival rate are influenced by the genotypic response of varieties to the corresponding agroclimatic conditions (the timing of the dormancy release and the duration of the growth decay period). In addition, the differentiation of buds by flower type in the spring and autumn periods leads to an increase in the proportion of dead explants and unstable development of meristematic apexes; therefore, it is recommended to use dormant buds with removed germinal burgeons as sources of explants in spring and autumn.

\section{References}

1. R. Brennan et al., Journal of Horticultural Science 64(6), 679-681 (1989) 
2. D. Ružić, T. Lazić, Agriculturae Conspectus Scientificus 71(4), 149-153 (2006)

3. V.A. Vysotsky, Pomiculture and small fruits culture in Russia 26, 3-10 (2011)

4. D. N. Skovorodnikov, F. F. Sazonov, Pomiculture and small fruits culture in Russia 26, 396-400 (2011)

5. E.V. Kolbanova, N.V. Kukharchik, Pomiculture and small fruits culture in Russia 26, 222-229 (2011)

6. G. K. Orazbaeva, V. T. Khasanov, R. A. Iskakov, V. K. Shvidchenko, Bulletin of S. Seifullin Kazakh Agro Technical University 1(72), 115-124 (2012)

7. E. Dziedzic, J. Jagła, Micropropagation of Rubus and Ribes spp. Protocols for Micropropagation of Selected Economically Important Horticultural Plants, 149-160 (2012)

8. O.A. Timofeeva, Yu.Yu. Nevmerzhitskaya, Clonal micro-propagation of plants: an educational and methodological guide, 56 (2012)

9. O.V. Matushkina, I.N. Pronina, L.V. Yarmolenko, S.A. Matushkin, Achievements of Science and Technology of AICis 1, 41-42 (2014)

10. M. M. Ishmuratova, L. A. Golovina, Bulletin of Udmurt University. Series "Biology. Earth Sciences" 27(4), 455-461 (2017)

11. L.A. Golovina, M.M. Ishmuratova, Biomics 10(4), 332-335 (2018) DOI: 10.31301/2221-6197.bmcs.

12. O.V. Matzneva, L.V. Tashmatova, V.V. Shakhov, Breeding and variety cultivation of fruit and berry crops 5(1), 71-73 (2018)

13. O.V. Matushkina, I.N. Pronina, S.A. Matushkin, L.V. Kruzhkova, Pomiculture and small fruits culture in Russia 61, 44-53 (2020). https://doi.org/10.31676/2073-4948-2020-6144-53

14. L. V. Tashmatova et al., E3S Web of Conferences 254, 04001 (2021)

15. N.V. Kukharchik, M.S. Kastritzkaya, S. E. Semenas, E. V. Kolbanova, T. A. Krasinskaya, N. N. Volosevich, O. V. Solovey, A. A. Smushko, T. N. Bozhiday, A.P. Rundia, A. M. Malinovskaya, Propagation of fruit and berry plants in vitro culture. In N.V. Kukharchik (Ed.) (2016)

16. V.V. Shakhov, L.V. Tashmatova, O.V. Matzneva, Contemporary horticulture, 4, 102105 (2017) Retrieved from http://journal.vniispk.ru/pdf/2017/4/39.pdf/ DOI: $10.24411 / 2218-5275-2017-00039$

17. E. N. Dzhigadlo, Methodical recommendations for using biotechnological methods in work with fruit, berry and ornamental crops (2005)

18. J. Dobránszk, J. A. Teixeira da Silva, Biotechnology Advances 28(4), 462-488 (2010) 